\title{
Frédéric Duval, Le français médiéval
}

\section{Maria Colombo Timelli}

\section{OpenEdition}

\section{Journals}

Édition électronique

URL : http://journals.openedition.org/studifrancesi/5511

DOI : 10.4000/studifrancesi.5511

ISSN : 2421-5856

\section{Éditeur}

Rosenberg \& Sellier

\section{Édition imprimée}

Date de publication : 1 septembre 2011

Pagination : 381

ISSN : 0039-2944

\section{Référence électronique}

Maria Colombo Timelli, «Frédéric Duval, Le français médiéval », Studi Francesi [En ligne], 164 (LV | II) |

2011, mis en ligne le 30 novembre 2015, consulté le 10 janvier 2021. URL : http://

journals.openedition.org/studifrancesi/5511 ; DOI : https://doi.org/10.4000/studifrancesi.5511

Ce document a été généré automatiquement le 10 janvier 2021.

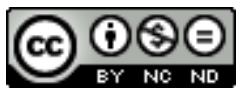

Studi Francesi è distribuita con Licenza Creative Commons Attribuzione - Non commerciale - Non opere derivate 4.0 Internazionale. 


\title{
Frédéric Duval, Le français médiéval
}

\author{
Maria Colombo Timelli
}

\section{RÉFÉRENCE}

FRÉDÉRIC DUVAL, Le français médiéval, Turnhout, Brepols, 2009 («L'Atelier du médiéviste», 11), $396 \mathrm{pp}$.

1 Spécifiquement destiné aux chercheurs et étudiants avancés en histoire médiévale, cet ouvrage ne sera cependant pas inutile aux étudiants et chercheurs en d'autres domaines. Il est divisé en quatre parties, qui toutes se signalent par certains traits d'originalité par rapport aux autres manuels de français médiéval disponibles.

La première section est éminemment historique; elle privilégie l'histoire externe du français, de ses origines au $\mathrm{Xv}^{\mathrm{e}}$ siècle, fait une large part à la variation, chronologique, régionale, sociale, stylistique, et surtout elle offre d'importants repères bibliographiques, avec rapide indication du contenu et de l'intérêt des études signalées (Parcours historique du français médiéval, pp. 11-66).

La deuxième partie s'approche d'une histoire interne du français médiéval, mais s'en distingue par quelques caractéristiques fondamentales: d'une part, il ne s'agit pas d'une description complète du système linguistique, mais elle privilégie les aspects essentiels, présentés sous forme de tableaux, de la morphologie et de la syntaxe; d'autre part elle porte essentiellement sur l'ancien français («la langue de la fin du Moyen Âge [rapprochant] sensiblement le français médiéval du français moderne», p. 69); surtout, elle essaie de prendre en compte l'ensemble des problèmes qui se posent au nonspécialiste dans la lecture des documents médiévaux: de l'identification des mots dans les manuscrits, aux questions relevant de la graphie, aux problèmes soulevés par le lexique. Ici encore, la bibliographie fournie est précieuse: elle comprend une longue série d'ouvrages de référence dans les domaines de la linguistique, de la phonétique, morphologie et syntaxe historiques, et particulièrement du lexique (voir notamment le paragraphe «outils consacrés au lexique», pp.94-112, qui comprend dictionnaires, 
bases de données et autres instruments difficilement signalés: dictionnaires de toponymes, d'anthroponymes etc.) (Comprendre le français médiéval, 67-161).

Suit un bref chapitre essentiel, consacré à quelques réflexions substantielles sur les pratiques éditoriales, sur les bibliographies médiévales et sur les grandes collections de textes, auxquelles s'ajoutent (p. 193) de précieuses indications sitographiques utiles pour la formation des historiens (et non seulement...) (le titre ne correspond que très imparfaitement au contenu: Textes en français médiéval, pp. 163-193).

5 La dernière partie est un recueil de textes: une cinquantaine d'extraits, du milieu du XII à la fin $\mathrm{du} \mathrm{XV}^{\mathrm{e}}$ siècle, retenus en raison de leur intérêt linguistique, y sont classés par fonctions («Connaître l'histoire», «Accéder au savoir», «Littérature de fiction», «Croire», «Droit et textes normatifs», «Documents de gestion interne», «Actes, lettres et inscriptions»); ils sont accompagnés d'un commentaire linguistique-lexical, graphique, morpho-syntaxique - plus ou moins développé en fonction des difficultés du texte en question, éventuellement d'une traduction intégrale. Le but pédagogique poursuivi est clair: il s'agit d'abord d'identifier des problèmes, puis de les résoudre à l'aide des instruments indiqués dans les sections précédentes (Anthologie commentée, pp. 197-376).

6 Complété par un Index bibliographique et par un Lexique des termes linguistiques, cet ouvrage, qui se veut modestement un «manuel», s'avère aussi très stimulant pour les historiens de la langue française (et-pourquoi pas?-de la littérature française médiévale), auxquels il offre la possibilité de réfléchir sur leurs méthodes de présentation des textes et sur des questions de base relevant de la diachronie et plus en général de la variation médiévale. 